\title{
THE PROPERTIES OF FOUR ELEMENTS IN ORLICZ-MUSIELAK SPACES
}

\author{
BARTOSZ MichERDA
}

\begin{abstract}
The property of four elements" $(P F E)$, closely related to the isotonicity of the metric projection operator, has been recently introduced and proved in ordered Hilbert spaces, $L_{p}$ spaces and Orlicz-Musielak spaces (see [5], [6], [12]). Moreover, a dual inequality named "the upper property of four elements" (UPFE) for norms in $L_{p}$-spaces has been discussed in [13].

In this paper we prove that the inequality (UPFE) holds in all Orlicz-Musielak spaces generated by a convex modular. It is also shown that both properties of four elements can be reversed (with some other constants) if the function generating the modular satisfies the condition $\left(\Delta_{2}\right)$. This generalizes Theorems 3.1, 3.4 from [13].
\end{abstract}

Mathematics subject classification (2000): 46E30, 41A65.

Key words and phrases: Inequalities, modular spaces, Orlicz-Musielak spaces, antiprojection operators, antiisotone operators.

\section{REFERENCES}

[1] AlBeRT YA. I., Generalized projection operators in Banach spaces: properties and applications, Functional Differential Equations, Proceedings of the Israel Seminar, Vol. I, Ariel, Israel (1994), 5-10.

[2] HaRauX A., How to differentiate the projection on a convex set in Hilbert space. Some applications to variational inequalities, J. Math. Soc. Japan 29 (1977), 615-631.

[3] HiRIart-UrRuty J. B., At what points is the projection mapping differentiable?, Amer. Math. Monthly 89 (1982), 456-460.

[4] Holmes R. B., Smoothness of certain metric projections in Hilbert spaces, Trans. Amer. Math. Soc. 184 (1973), 87-100.

[5] ISAC G., On the order monotonicity of the metric projection operator, Approximation Theory, Wavelets and Applications (Ed. S. P. Singh), Kluwer Academic Publishers, NATO ASI Series (1995), 365-379.

[6] ISAC G. AND LEWICKI G., On the property of four elements in modular spaces, Acta Math. Hungar. 83 (4) (1999), 293-301.

[7] IsAC G. AND NEMETH A. B., Monotonicity of metric projections onto positive cones in ordered Euclidean spaces, Ark. Math. 46 (1986), 568-576.

[8] ISAC G. AND NEMETH A. B., Every generating isotone projection cone is latticial and correct, J. Math. Anal. Appl. 147 (1990), 56-62.

[9] IsAC G. AND NEMETH A. B., Isotone projection cones in Hilbert spaces and the complementarity problem, Boll. Un. Math. Ital. 7 (1990), 773-802.

[10] IsaC G. And Nemeth A. B., Projection methods, isotone projection cones and the complementarity problem, J. Math. Anal. Appl. 153 (1990), 258-275.

[11] IsAC G. AND NEMETH A. B., Isotone projection cones in Euclidean spaces, Ann. Sci. Math. Québec 16 (1) (1992), 35-52.

[12] ISAC G. AND PERSSON L. E., On an inequality related to the isotonicity of the projection operator, J. Approx. Theory 86 Nr. 2 (1996), 129-143.

[13] ISAC G. AND PERSSON L. E., Inequalities related to isotonicity of projection and antiprojection operators, Math. Ineq. Appl. 1 Nr. 1 (1998), 85-97.

[14] KuCZMa M., An Introduction to the Theory of Functional Equations and Inequalities, PWN, 1985.

[15] MusielaK J., Orlicz Spaces and Modular Spaces, Lecture Notes in Math. v. 1034, Springer-Verlag, 1983. 